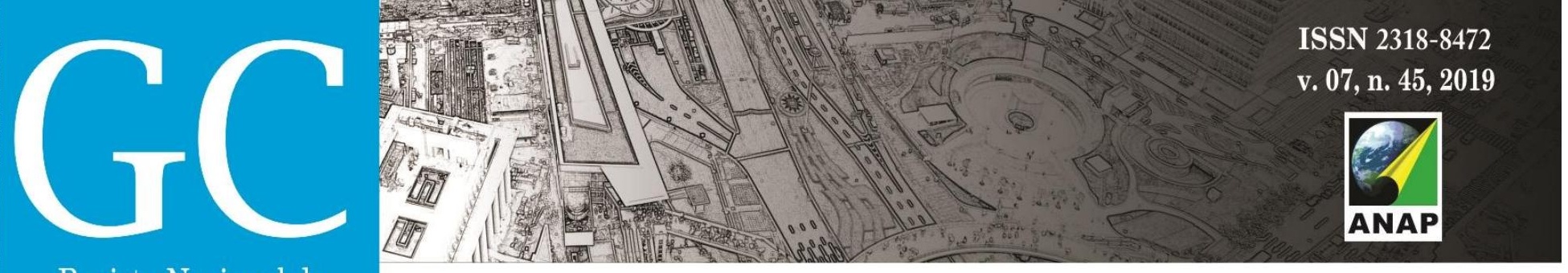

Revista Nacional de

Gerenciamento de Cidades

\title{
O Patrimônio Cultural e o Plano Diretor de Visconde do Rio Branco-MG
}

The Cultural Heritage and the Master Plan of Visconde do Rio Branco-MG-Brazil

El Patrimonio Cultural y el Plan General de Visconde do Rio Branco-MG

Ítalo Itamar Caixeiro Stephan

Professor Doutor, UFV, Brasil stephan@ufv.br

Camilla Magalhães Carneiro

Mestranda, UFV, Brasil camilla.magalhaes@ufv.br 


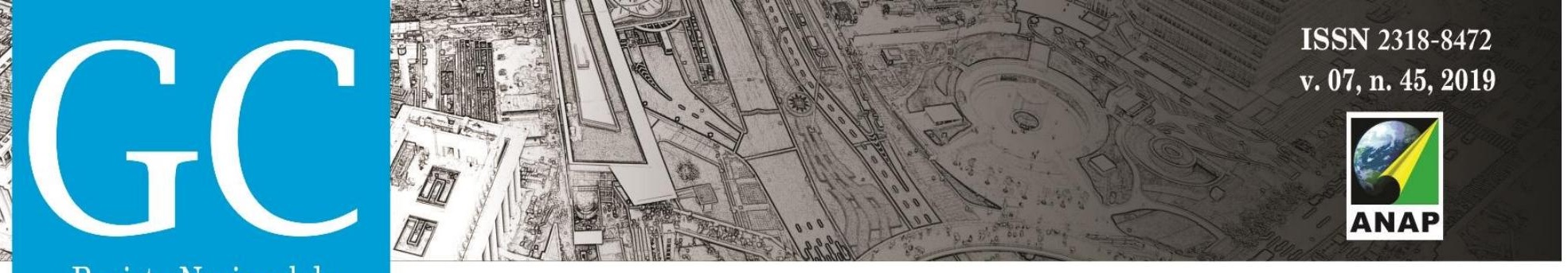

Revista Nacional de

Gerenciamento de Cidades

\section{INTRODUÇÃO}

Visconde do Rio Branco é um município da Zona da Mata mineira. Limita-se ao norte com o município de São Geraldo, ao leste com o município de Guiricema, ao sul, com o município de Guidoval, a oeste com o município de Divinésia, a noroeste com o município de Paula Cândido e a sudeste com o município de Ubá (Figura 1).

Figura 1: Limites do município de Visconde do Rio Branco, MG.

Figura 2: Localização de Visconde do Rio Branco na

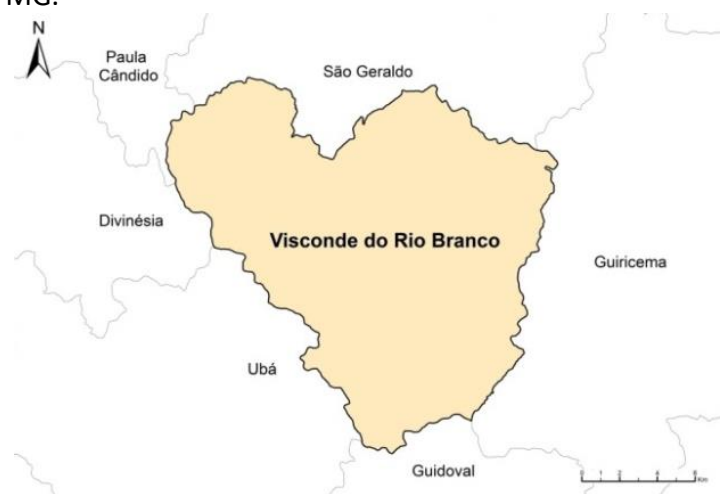

FONTE: Revisão do Plano Diretor e elaboração do Plano de Mobilidade Urbana de Visconde do Rio Branco, MG. microrregião de Ubá.

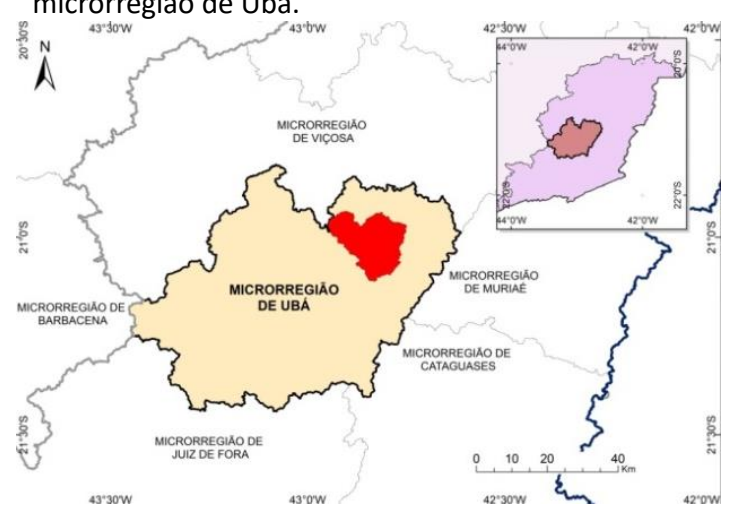

FONTE: Revisão do Plano Diretor e elaboração do Plano de Mobilidade Urbana de Visconde do Rio Branco, MG.

Segundo Oiliam José (1982), a colonização do município se deu em meados do século XVIII, com os bandeirantes. O município de Visconde do Rio Branco foi criado em 16 de março de 1839, com a denominação de São João Batista do Presídio. Foi, no entanto, suprimido pela lei provincial, passando a pertencer à povoação de São Januário de Ubá (atual município denominado Ubá). Isso ocorreu duas vezes, até ser restabelecido como território desmembrado de Ubá em 22 de setembro de 1881, sob a designação de Visconde do Rio Branco.

Segundo dados do IBGE (Instituto Brasileiro de Geografia e Estatística), a população do município em 2010 era de 37.942 habitantes, sendo que a população estimada de 2018 era de 42.149 habitantes.

Visconde do Rio Branco possui um importante acervo cultural, incluindo fazendas, casarões, conjuntos arquitetônicos, praças, dentre outros. Em 2017, existiam 14 bens tombados, quando o Conselho entrou com o processo de tombamento de mais 28 bens. Em sua maioria são exemplares de uma arquitetura eclética bem elaborada, das primeiras décadas do Século XX. 


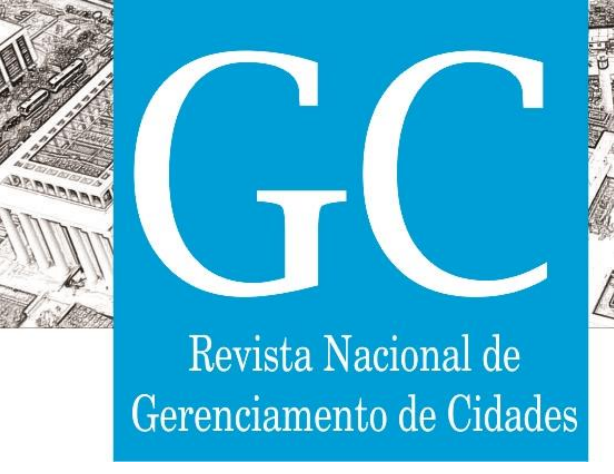

- Identificação dos instrumentos legais referentes à proteção desse Patrimônio;

- Busca de referencial teórico sobre planos diretores, aplicação de planos diretores e políticas de preservação do patrimônio cultural;

- Obtenção de uma cópia do Plano Diretor de Visconde do Rio Branco (PDVRB);

- Identificação dos artigos do Plano Diretor com referência ao Patrimônio Cultural;

- Análise dos dispositivos do artigo 42 do Estatuto da Cidade, a fim de verificar sua aplicação no Plano estudado, com vistas à preservação do Patrimônio Cultural;

- Identificação de conteúdo ausente no PDVRB, referente à proteção do patrimônio cultural;

- Reuniões com representantes do Conselho Municipal de Patrimônio e do setor de aprovação de projetos da Prefeitura.

Análise dos dados levantados.

\section{O PATRIMÔNIO CULTURAL DE VISCONDE DO RIO BRANCO}

Dentre os bens importantes localizados no município, se destaca o Conservatório Estadual de Música ${ }^{1}$ (Figura 2), e o Museu Municipal de Visconde do Rio Branco (Figura 3), além dos demais bens que compõem um significativo acervo arquitetônico. Dentre os bens tombados, estão trinta e cinco edificações, um conjunto urbano, dois conjuntos paisagísticos, uma estrada e uma árvore, além de seis monumentos².

Figura 4: Conservatório Estadual de Música "Prof. Theolindo José Soares"

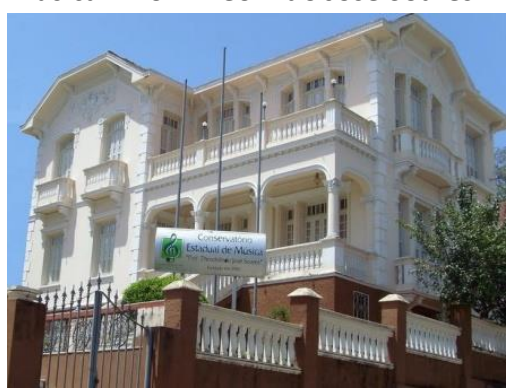

Fonte: acervo dos autores.
Figura 5: Museu Municipal de Visconde do Rio Branco

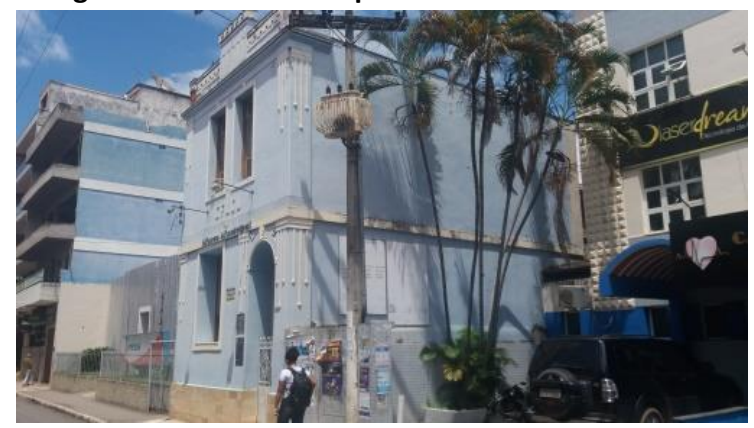

Fonte: acervo dos autores.

Entretanto, o crescimento urbano compromete a integridade desse importante acervo, especialmente o entorno da Praça 28 de Setembro (Figuras 4 e 5), onde, por falta de regras,

\footnotetext{
${ }^{1}$ O Conservatório Estadual de Música "Prof. Theolindo José Soares" é formador de músicos desde 1956 e que abriga, aproximadamente, 1800 alunos.

2 Informações obtidas junto ao Conselho Municipal do Patrimônio Histórico e Artístico de Visconde do Rio Branco.
} 


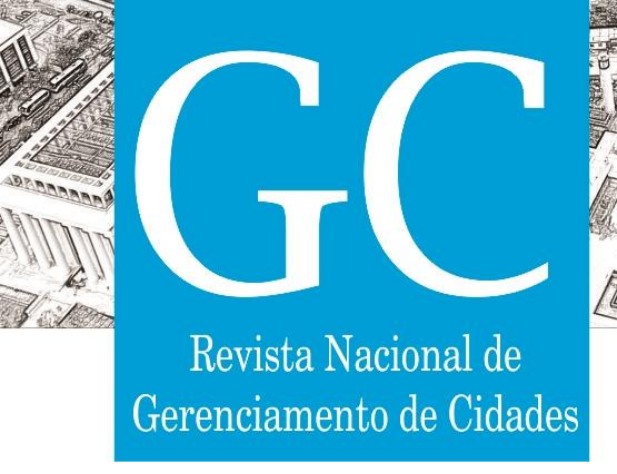

ISSN 2318-8472

começou um processo de verticalização, com prédios que ocupam a totalidade dos seus terrenos. Isso faz com que sejam necessários o aperfeiçoamento e a instrumentação em políticas urbanas que assegurem a preservação do Patrimônio Cultural do município, que devem ser abordadas no Plano Diretor e em legislação complementar. A esse conjunto, cabe propor o uso de instrumentos mais adequados à realidade local, de forma a conciliar o crescimento urbano com a preservação.

Figura 6: edificação histórica em meio a prédios verticalizados, na Praça 28 de Setembro

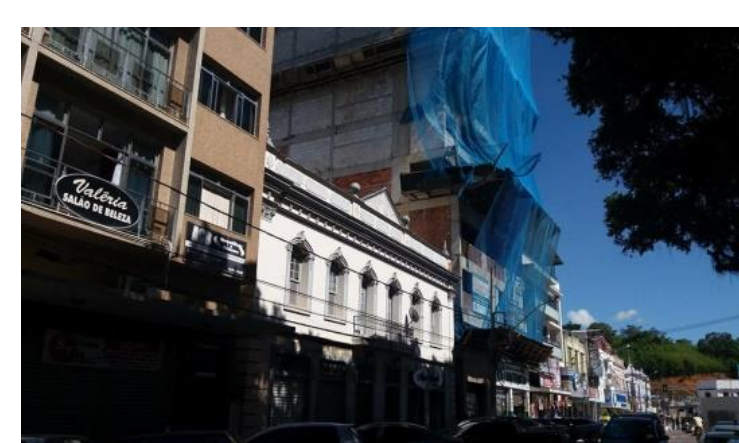

Fonte: acervo dos autores.
Figura 7: local na Praça 28 de Setembro, onde existia uma edificação histórica, e que dará lugar a um prédio verticalizado

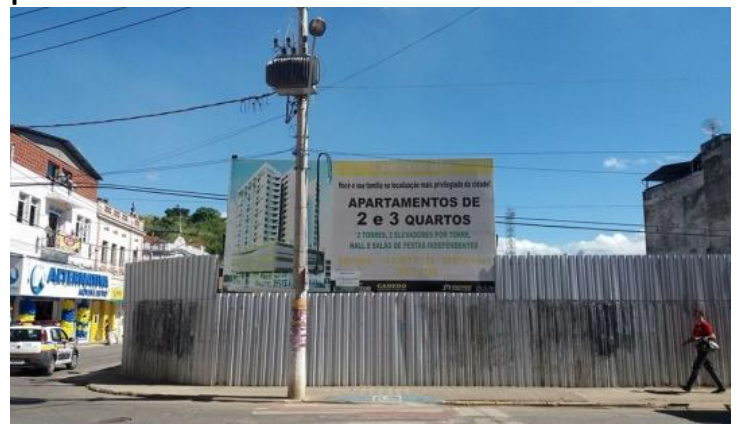

Fonte: acervo dos autores.

Figura 8: fachada do prédio que ocupará o terreno exibido na Figura 7. A fachada reproduz edificação histórica que existia no local e que foi demolida.

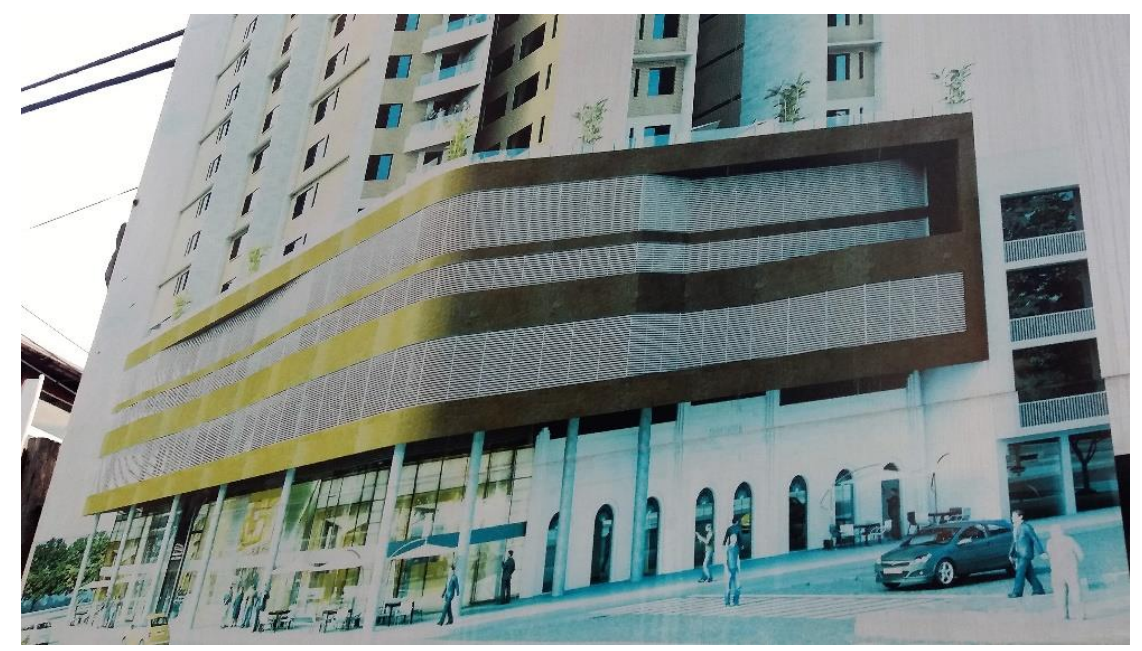

Fonte: acervo dos autores. 


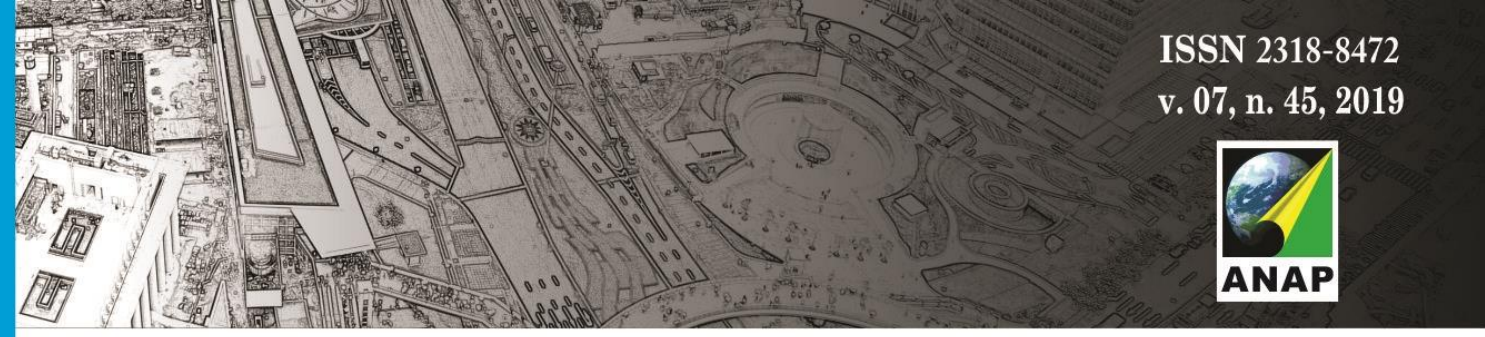

Revista Nacional de

Gerenciamento de Cidades

Segundo Teixeira (2017), "a primeira lei do município que estabelecia a proteção do patrimônio foi promulgada em 1991, visando à proteção do patrimônio histórico e artístico de Visconde do Rio Branco, além de autorizar a criação de um Conselho [...]", especialmente em seu artigo 190. Outra política também foi importante para o incentivo à preservação: a Lei Estadual no 12.040, de 28 de dezembro de 1995 (mais conhecida como Lei Robin Hood ${ }^{3}$ ), que estabelece critérios para a distribuição dos recursos advindos do recolhimento do ICMS Cultural (imposto sobre circulação de mercadorias e serviços).

Segundo Silva et al. (2018), o exercício de repasse do ICMS para os municípios é de grande valor, pois incentiva a cultura local, além de ser um "instrumento motivador para proteção do patrimônio tombado, inventariado, registrado ou em atividades de educação patrimonial".

\title{
4 O PLANO DIRETOR COMO INSTRUMENTO DE PROTEÇÃO AO PATRIMÔNIO CULTURAL
}

Desde o advento do Estatuto da Cidade, lei no 10.257, aprovada em 2001, se tornou obrigatória a elaboração do Plano Diretor, dentre outros critérios, de cidades com mais de 20.000 habitantes. Para o cumprimento dessa exigência, foi estabelecido um prazo, que se estendeu até outubro de 2006.

Visconde do Rio Branco compunha a parcela de municípios que devia elaborar obrigatoriamente seu Plano Diretor, teve este aprovado sob a forma de Lei Complementar, em 29 de dezembro de 2006. Estava estabelecido que sua revisão acontecesse em um prazo máximo de 10 anos, porém ela só teve início nos primeiros meses de 2018.

O Plano Diretor tem grande potencial na conciliação da preservação do patrimônio histórico com o crescimento urbano. É importante que esse instrumento de planejamento tenha como um de seus objetivos valorizar o patrimônio cultural. Para Ferreira (2017, p. 79),

\begin{abstract}
O Plano Diretor pode ser usado como instrumento de universalização do patrimônio histórico, cultural e arquitetônico; além de criar diretrizes para a preservação, ele pode auxiliar no desenvolvimento de ações que possam gerar atividades econômicas, como o turismo, contribuindo para a complementação de renda dos habitantes.
\end{abstract}

Além disso, o Plano Diretor deve ser um meio para evidenciar alternativas que atenuem o efeito da especulação imobiliária.

Especificamente para as cidades históricas existem ferramentas apropriadas que servem de estímulo à preservação como: isenção de IPTU, Transferência do Direito de Construir (TDC), direito de preempção, dentre outros benefícios fiscais que podem auxiliar na conservação do patrimônio edificado. (CELESTINO, 2012, p. 10)

\footnotetext{
${ }^{3}$ Segundo a Fundação João Pinheiro, "a Lei Robin Hood define os critérios de distribuição dos recursos do ICMS/IPIexportação para os municípios de Minas Gerais com os objetivos de melhorar a distribuição da receita arrecadada com o imposto e promover o desenvolvimento de políticas públicas em âmbito municipal".
} 


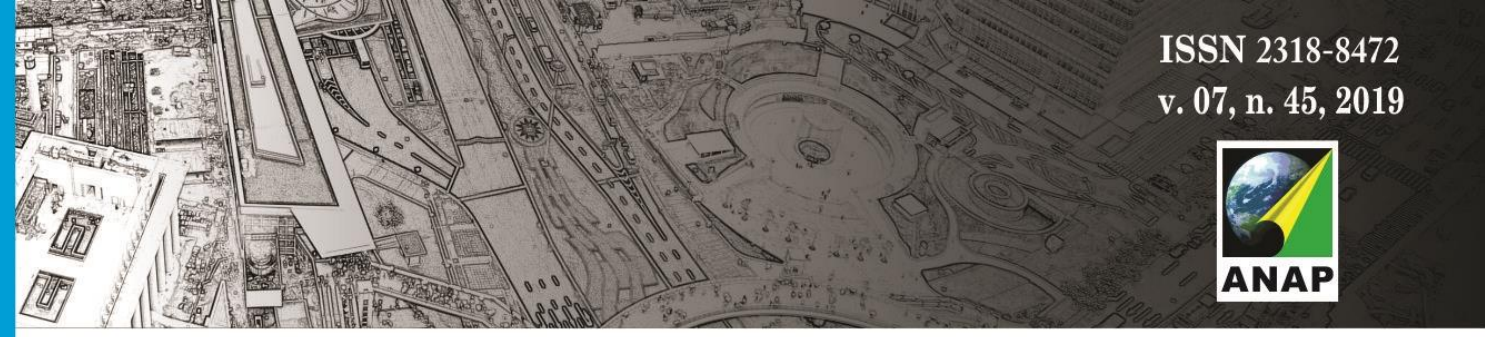

Revista Nacional de

Gerenciamento de Cidades

Entretanto, há muitas dificuldades na aplicação dos Planos Diretores e na conciliação do crescimento urbano com a preservação do Patrimônio Cultural. Dessa forma, buscou-se, através deste trabalho, analisar a situação em Visconde do Rio Branco, a fim de contribuir para sua revisão iniciada em 2018 e para a reflexão sobre o processo de planejamento urbano, com vistas à preservação do Patrimônio Cultural.

Para avaliar sua aplicação foi feito um recorte, avaliando-se os dispositivos relacionados à proteção do patrimônio cultural. Foi analisado também o artigo 42 do Estatuto da Cidade, o qual prevê o conteúdo mínimo que um Plano Diretor deve conter, considerando a preservação do patrimônio cultural. Sendo assim, foi identificado como os dispositivos desse artigo foram elaborados no Plano Diretor e como acontece na realidade.

\title{
5 AS DIFICULDADES PARA A APLICAÇÃO DOS PLANOS DIRETORES
}

Segundo a definição do Plano Diretor de Visconde do Rio Branco, de 2006:

\begin{abstract}
O Plano Diretor é o instrumento estratégico orientador da política urbano-rural sob a competência do Município, contendo as diretrizes urbanísticas e os respectivos fundamentos jurídicos que permitem ordenar o crescimento das áreas urbanizadas, urbanizáveis e de expansão, conferindo-Ihes desenvolvimento urbano-rural com qualidade de vida compatível à dignidade dos seus munícipes.
\end{abstract}

Os objetivos abordados nessa definição são comuns às dos demais municípios brasileiros, e orientam na elaboração de seus Planos Diretores. Entretanto, a oferta da referida "qualidade de vida", muitas vezes, fica restrita a uma parcela da população, além de não abranger os aspectos culturais. Estes, constantemente, são vistos como entrave ao crescimento, quando, na verdade, são aspectos potenciais para o desenvolvimento.

Segundo Maricato (2006), "a experiência histórica com planos diretores no Brasil mostra que eles se aplicam apenas a uma parte da cidade, tomam o mercado como referência e ignoram a demanda da maior parte da sociedade, bem como ignoram a cidade ilegal". Entretanto, como diz a mesma autora: "[...] é uma oportunidade única para ampliar o debate político e para formar militantes para a luta por uma cidade mais justa". Essa discussão leva ao questionamento da eficiência do planejamento urbano brasileiro. Sendo assim, é preciso que haja avaliações constantes dos Planos Diretores, à medida que eles forem elaborados, revistos e aprovados, a fim de identificar aspectos positivos e negativos que possam contribuir para seu aperfeiçoamento.

Um dos aspectos a serem analisados é a constatabilidade ${ }^{4}$ do conteúdo de uma lei. A existência de dispositivos contatáveis facilita a identificação do cumprimento, ou não, dos itens abordados. Porém, o fato de um Plano Diretor ser dotado de dispositivos constatáveis não garante sua aplicação. Muitas vezes, eles são carregados de itens generalistas, o que facilita sua aprovação por parte de uma parcela da população, em sua maioria com interesses imobiliários. Segundo

\footnotetext{
${ }^{4}$ Entende-se por constatabilidade a qualidade referente à possibilidade de verificar a aplicação de determinado dispositivo.
} 


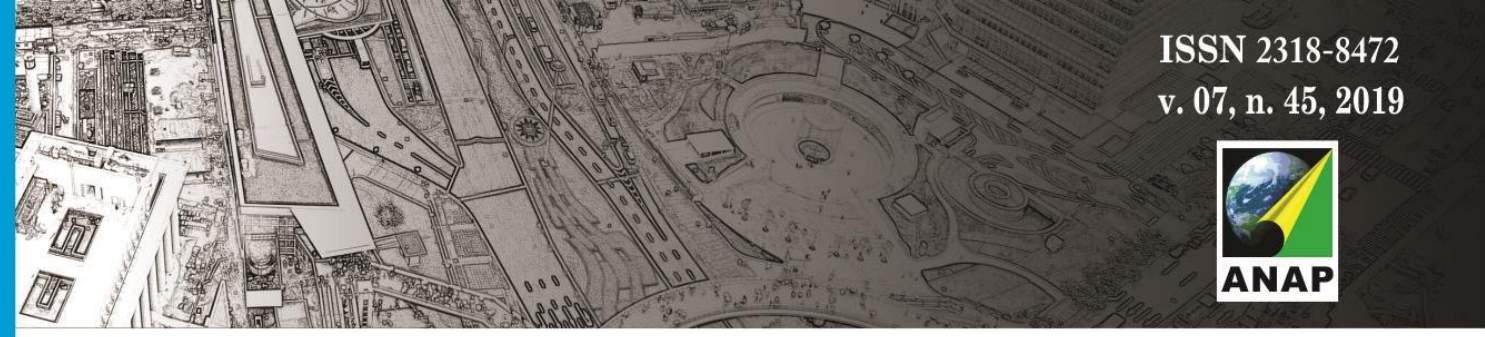

Revista Nacional de

Gerenciamento de Cidades

Stephan (2006): "a característica da autoaplicabilidade não garante a aplicação. Entretanto, um dispositivo autoaplicável presente num plano diretor é uma referência segura para que seja cobrada a sua aplicação".

Dessa forma, é preciso que trabalhos de análise da aplicação dos Planos sejam feitos e divulgados para a população. A forma como as leis são elaboradas e divulgadas (quando o são), muitas vezes, gera dúvidas que não são facilmente esclarecidas. Isso contribui para a alienação da população nos processos decisivos do meio em que vive, o que pode facilitar para que interesses particulares prevaleçam.

O Estatuto da Cidade impõe o que se deve buscar com um Plano Diretor, assim como determina o mínimo que o mesmo deve conter:
Art. 42. O plano diretor deverá conter no mínimo: de demanda para utilização, na forma do art. 50 desta Lei;
II - disposições requeridas pelos arts. 25, 28, 29, 32 e 35 desta Lei;
III - sistema de acompanhamento e controle.

I - a delimitação das áreas urbanas onde poderá ser aplicado o parcelamento, edificação ou utilização compulsórios, considerando a existência de infra-estrutura e

Entretanto, mesmo com as exigências citadas acima, é preciso atentar-se para que os Planos sejam objetivos e claros, evitando o adiamento de obrigações, bem como a distorção das suas finalidades. Além disso, é importante que toda a população seja capaz de ler e interpretar seus instrumentos.

Santos Júnior e Montandon afirmam que há orientação expressa para que os Planos Diretores sejam autoaplicáveis, principalmente quanto aos instrumentos de planejamento urbano. No entanto, na ampla pesquisa desenvolvida pela Rede de Avaliação e capacitação para a implementação dos Planos Diretores Participativos ${ }^{5}$, identificou-se como insuficientes a definição de conceitos e parâmetros urbanísticos, a definição de prazos, a operacionalização de procedimentos administrativos e a demarcação das áreas de aplicação no território. Quanto a esse último aspecto, os autores creditam como principal motivo as deficiências da capacidade técnica e institucional dos municípios. Em outras palavras, a fragilidade institucional da capacidade de gestão do município. (SANTOS JÚNIOR E MONTANDON, 2011, p.35-36).

Em avaliação da aplicação de planos diretores em Minas Gerais, Stephan, Reis e Rocha destacam a quase total ausência dos instrumentos previstos no Estatuto da Cidade sob formas autoaplicáveis. Foi identificado que a maioria dos planos foi elaborada por assessorias contratadas. Isso pode ter dificultado a sua aplicação, uma vez que as prefeituras não dispunham dos recursos humanos necessários para a implementação do plano. Para os autores, há dois aspectos fundamentais: o primeiro se trata da elaboração e, principalmente, da aplicação do plano, quando devem ser fornecidas condições de funcionamento, treinamento e capacitação

\footnotetext{
${ }^{5}$ A Rede Nacional de Avaliação e Capacitação para Implementação de Planos Diretores Participativos faz parte de um conjunto de ações coordenadas pela Secretaria Nacional de Programas Urbanos (SNPU) para apoiar a implementação do Estatuto da Cidade nos municípios brasileiros.
} 


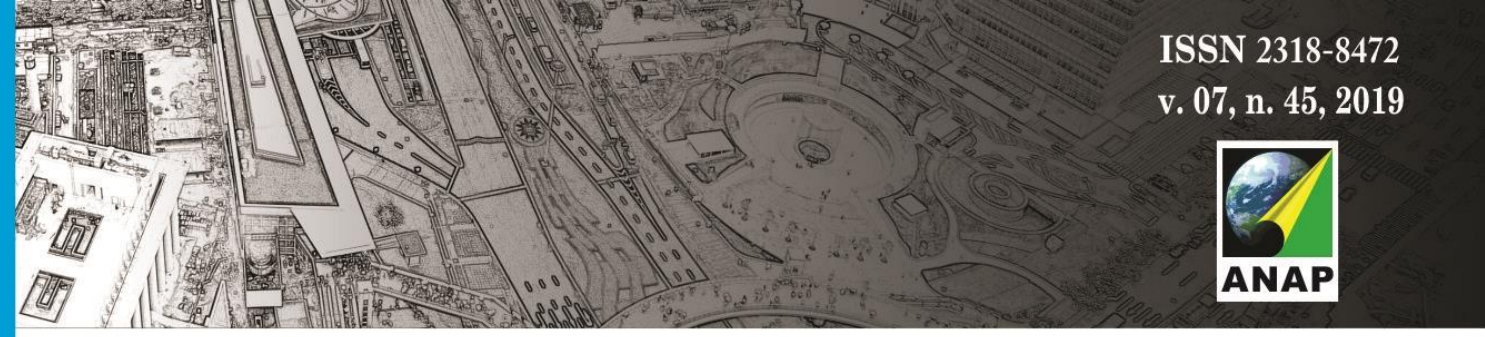

Revista Nacional de

Gerenciamento de Cidades

aos envolvidos nas atividades correlatas ao planejamento urbano. Em relação ao outro aspecto, enfatizam que é fundamental que exista em cada prefeitura uma estrutura mínima de planejamento urbano (STEPHAN, REIS e ROCHA, 2012).

Entretanto, ainda se tratando de planejamento urbano, há um desafio no que se refere à integração das políticas. É perceptível um distanciamento dos órgãos de preservação dos órgãos de desenvolvimento, e isso é dificultado à medida que há a ausência de importantes instrumentos nos Planos, como um zoneamento que delimite a área de preservação do Patrimônio Cultural. Sendo assim, se agrava a dificuldade na correta instrumentação e aplicabilidade dos instrumentos do Estatuto da Cidade.

Castriota (2009, p.90) também ressalta a importância de integração das políticas urbanas:

[...] é fundamental a integração absoluta entre a política específica de preservação do meio ambiente urbano e a política de um modo geral. Ao se pensar em termos de preservação ambiental, deve-se tentar harmonizar sítios e edificações preexistentes com as novas, utilizando-se para isso os instrumentos urbanísticos mais gerais, como o Plano Diretor para o município, a Lei de Uso e Ocupação do Solo, os códigos de obras e posturas, dentre outros.

O Artigo 42 do Estatuto da Cidade define o mínimo que um Plano Diretor deve conter. Dessa forma, buscou-se também analisar o Plano em questão de forma a verificar se o mesmo contemplava as exigências citadas nessa lei. Isso se deve ao fato de que o ordenamento do território, a partir do que é requerido no Estatuto da Cidade, interfere diretamente, na preservação do Patrimônio Cultural. Sendo assim, com o cumprimento do que é estabelecido no Artigo 42, é possível que sejam elaboradas políticas que conciliem o crescimento urbano com a preservação. Isso confere respaldo aos gestores públicos nas decisões que afetam todo o município, como aquelas que definem regras de uso e ocupação do solo mais adequadas. 0 Estatuto da Cidade também prevê, em seu Art. $2^{\circ}$, que

\footnotetext{
"A política urbana tem por objetivo ordenar o pleno desenvolvimento das funções sociais da cidade e da propriedade urbana, mediante as seguintes diretrizes gerais:

VI - ordenação e controle do uso do solo, de forma a evitar:

a) a utilização inadequada dos imóveis urbanos;

b) a proximidade de usos incompatíveis ou inconvenientes;

XII - proteção, preservação e recuperação do meio ambiente natural e construído, do patrimônio cultural, histórico, artístico, paisagístico e arqueológico;
}

Entende-se aqui, a partir dos dispostos nos dois incisos, que uma cidade que tem um acervo arquitetônico, especialmente na forma de conjunto, a ordenação do solo deve prever a criação de uma zona de proteção histórica, formada a partir da fusão das áreas de entorno dos bens tombados. 


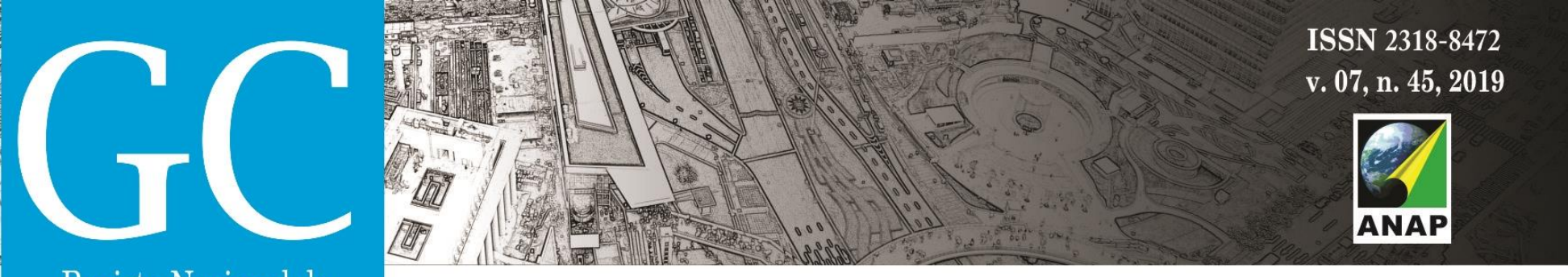

Revista Nacional de

Gerenciamento de Cidades

\section{INFORMAÇÕES SOBRE O PLANO DIRETOR DE VISCONDE DO RIO BRANCO}

O PDVRB foi aprovado através da Lei Complementar no 23, de 29 de dezembro de 2006, e pode ser acessado facilmente através do site da Câmara Municipal. Foi realizado através de assessoria dos professores do Departamento de Arquitetura e Urbanismo da Universidade Federal de Viçosa (UFV), e sua elaboração incluiu a nomeação de uma equipe local, realização de curso de capacitação, leituras comunitária e audiências públicas em vários bairros e áreas rurais, além de reuniões temáticas. Sua revisão deveria ocorrer dentro do prazo máximo de dez anos, porém esta só teve início em 2018, também pela equipe da UFV.

O Plano é abrangente, apresenta diretrizes sobre vários temas: política, objetivos, diretrizes e instrumentos para os setores agropecuário, saneamento básico; energia e iluminação pública, desenvolvimento econômico, científico e tecnológico. Apresenta políticas de trabalho, emprego e renda, de saúde, educação, assistência social e cidadania, cultura, esportes, lazer e turismo, abastecimento e defesa civil.

Os pontos básicos de política urbana constantes do Plano Diretor são: as diretrizes físicoterritoriais, o meio ambiente, o sistema viário, o mobiliário urbano e a política de planejamento e gestão.

Em sua estrutura são observadas muitas definições, porém algumas delas não possibilitam a cobrança da aplicação de seus objetivos. Isso faz com que seja necessária sua revisão, prevista no mesmo para acontecer a cada dez anos.

\section{O PATRIMÔNIO CULTURAL NO PLANO DIRETOR DE VISCONDE DO RIO BRANCO}

Segundo o Ministério das Cidades, o plano diretor deve tratar a cidade como um todo e em relação à proteção de seu patrimônio cultural, deve ser "impregnado" com a ideia de conservação. Sendo assim, estabelece recomendações importantes. A primeira é que a cidade deve ser tratada além de suas áreas históricas, a dinâmica urbana deve ser considerada em sua totalidade ${ }^{6}$. Em segundo lugar, considera que os inventários culturais devem ser vistos como poderosos instrumentos na formulação do plano. Em termos de propostas, "deve-se recorrer à tradição do nosso urbanismo, que sempre utilizou mecanismos como o estabelecimento de tipologias, modelos e gabaritos, para, numa perspectiva de conservação, compatibilizar as novas inserções e as preexistentes." Ainda segundo o Ministério, os planos diretores devem propor instrumentos e ações estratégicas para que as áreas históricas cumpram ou continuem a cumprir sua função social, garantindo a preservação e a diversidade da população no local (BRASIL, 2008, p. 55 -57).

Para este trabalho, foram selecionadas algumas seções do Plano Diretor que estão ligadas ao Patrimônio Cultural, sendo elas: "Patrimônio Histórico, Artístico e Cultural", "Educação", "Cultura", "Esporte, Lazer e Turismo". Nesse conjunto, se encontram as seções de "Educação" e "Esporte, turismo e lazer", devido ao potencial de suas políticas para promover ações que

\footnotetext{
${ }^{6}$ Essa falta de cuidado tem acontecido com as cidades "históricas" coloniais como Ouro Preto, Diamantina, Serro ou Tiradentes, onde as áreas externas a elas padecem gravemente de planejamento urbano adequado.
} 


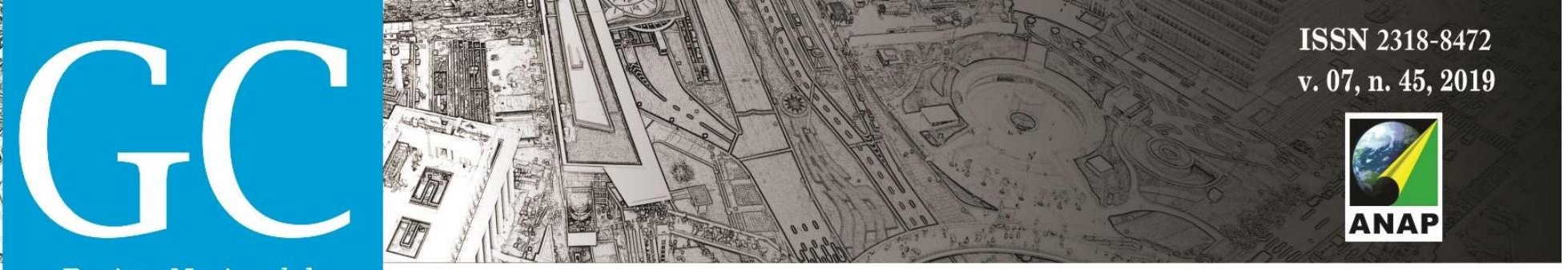

Revista Nacional de

Gerenciamento de Cidades

integrem a comunidade. Dentro destes temas foram destacados 21 dispositivos, os quais tiveram sua constatabilidade verificada.

Dentro dos 21 dispositivos analisados, apenas 2 foram considerados constatáveis, representando 9,52 por cento do total. Os dispositivos não constatáveis somaram um total de 19, o que representa 90,48 por cento do total. Os dispositivos constatáveis não foram aplicados. O Quadro 1 resume essas informações:

Quadro 1: Análise dos Artigos/Incisos do Plano Diretor de Visconde do Rio Branco referentes a Patrimônio Cultural.

\begin{tabular}{|c|c|c|c|c|}
\hline \multicolumn{5}{|c|}{ Total de dispositivos analisados: 79 } \\
\hline & Constatáveis & Não constatáveis & $\begin{array}{c}\text { Constatáveis } \\
\text { Aplicados }\end{array}$ & $\begin{array}{c}\text { Constatáveis Não } \\
\text { aplicados }\end{array}$ \\
\hline Número de itens & 2 & 19 & 0 & 2 \\
\hline Percentual & $9,52 \%$ & $90,48 \%$ & $0 \%$ & $100 \%$ \\
\hline
\end{tabular}

Fonte: acervo dos autores.

O Quadro 2 apresenta uma compilação dos dispositivos que tratam do patrimônio arquitetônico no PDVRB. 


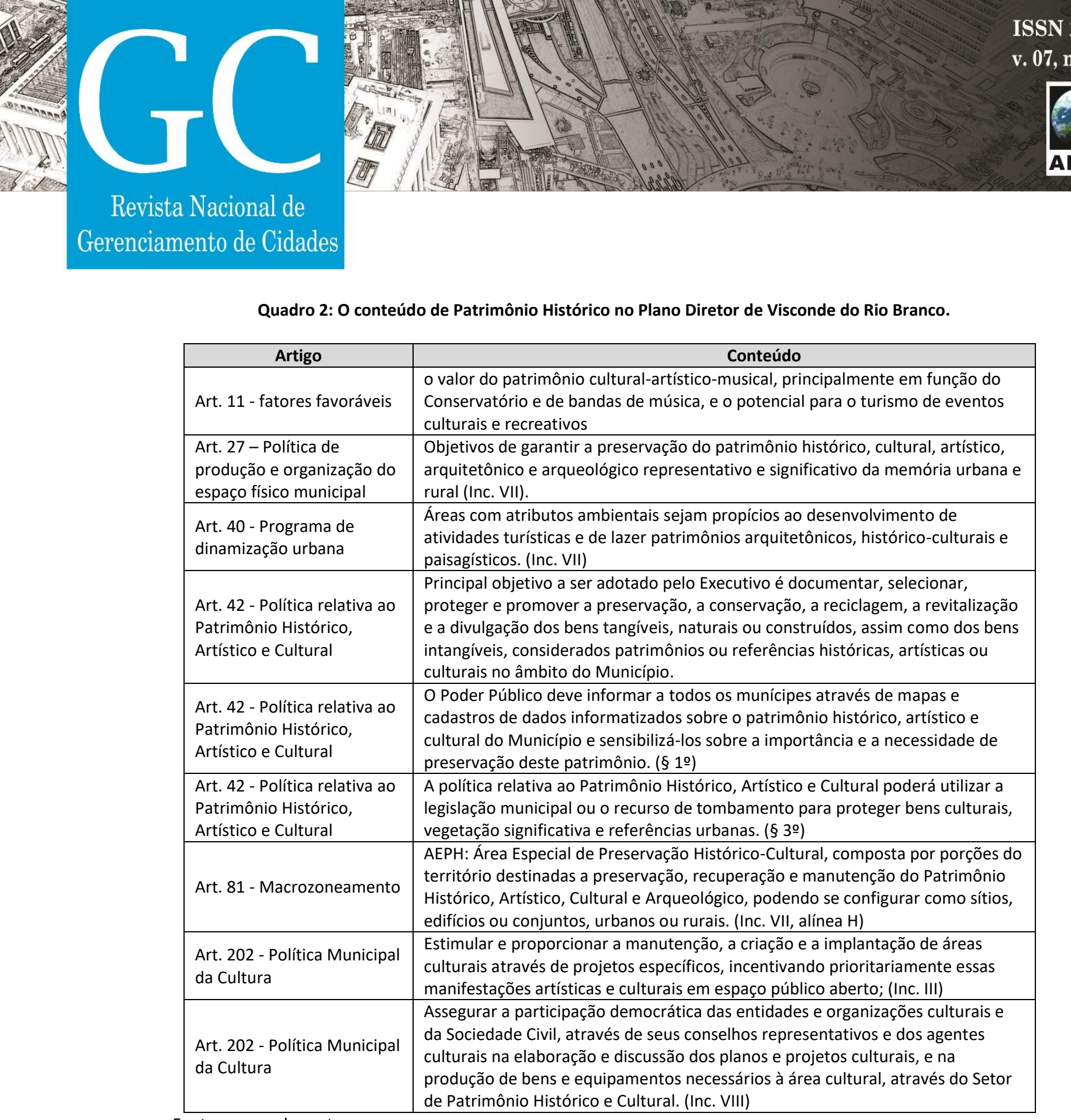

Fonte: acervo dos autores.

Há uma seção, com um único artigo, destinada à Política relativa ao Patrimônio Histórico, Artístico e Cultural. No Macrozoneamento foi prevista a criação de Área Especial de Preservação Histórico-Cultural (AEPH), composta por porções do território destinadas a preservação, recuperação e manutenção do Patrimônio Histórico, Artístico, Cultural e Arqueológico. O PDVRB inclui os instrumentos previstos no Artigo 42 do Estatuto da Cidade (Vide Quadro 3). 


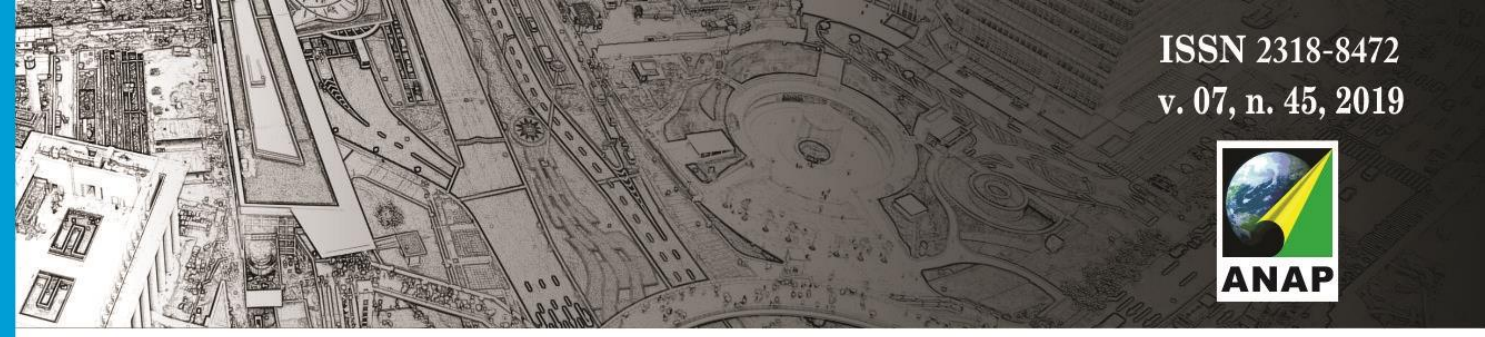

Revista Nacional de

Gerenciamento de Cidades

Durante a análise, foi percebido que o Plano contempla muitos aspectos de forma generalizada, que dificultam o seu cumprimento, pois dá margem à sua não execução. Isso acontece à medida que não são estabelecidas obrigações e prazos não são determinados.

Há que se notar a falta de algumas questões no único artigo da Seção VIII - do Patrimônio Histórico, Artístico e Cultural que trata especificamente do assunto. A primeira deveria ser algum tipo de esforço na ampliação e manutenção de pontuação, junto ao ICMS Cultural do Estado, condizente com o significativo acervo cultural de Rio Branco. Em segundo lugar, caberia incluir a necessidade da prática de programas de educação patrimonial. Um terceiro ponto deveria ser a inclusão de incentivos para a preservação do patrimônio arquitetônico e as possibilidades do uso de instrumentos como a Transferência do Direito de Construir e o Direito de Preempção. Outro ponto importante seria incluir o estimulo e a manutenção do funcionamento do Conselho Municipal do Patrimônio Histórico e Artístico - COMPHAR. Ainda caberia garantir que todos os projetos arquitetônicos que estejam em AEPH ou nas áreas de entorno de bens tombados sejam analisados pelo COMPHAR, além da tramitação normal na Prefeitura.

Em relação aos dispositivos do artigo 42 do Estatuto da Cidade, percebeu-se que o Plano Diretor os aborda, explicando suas finalidades, mas, no que se refere à sua implantação, cita uma lei não elaborada (Lei de Uso e Ocupação do Solo), o que, segundo os analistas da Prefeitura, traz inúmeras dificuldades na análise e aprovação de projetos de construção. Além disso, atribui a adoção de medidas cabíveis para o alcance dos demais objetivos citados a outros órgãos, o que contribui para o adiamento, ou mesmo para a não adoção de tais medidas. A partir da análise dos assuntos relativos ao Patrimônio Cultural, percebe-se que nem sempre os dispositivos constatáveis, e com diretrizes precisas, são aplicados. Tais dispositivos dependem do interesse do poder público para entrar em vigor, assim como dependem do conhecimento, interesse e cobrança pela população.

O direito de preempção, a transferência do potencial construtivo e as operações urbanas seriam instrumentos importantes na proteção do patrimônio arquitetônico e urbanístico. Para sua aplicação, esses precisam ser regulamentados. Antes disso, seriam identificadas as duas áreas: as com acervo arquitetônico a ser protegido e as que possuam infraestrutura adequada para serem receptoras do potencial construtivo.

Há também a carência de instrumentos de ordenamento territorial que abranjam as questões da convivência do crescimento urbano com a preservação. Isso faz com que a população, assim como os gestores do município, não disponham de instrumentos necessários para garantir o crescimento sustentável do município. Os instrumentos de zoneamento e controle do uso e ocupação do solo necessitam de elaboração e regulamentação. Nestas, seria fundamental a criação das áreas de proteção histórica previstas no Plano de 2006, com restrições à verticalização e com taxas de ocupação do solo e afastamentos, por exemplo, compatíveis com a coexistência entre as diferentes fases da história de Visconde do Rio Branco.

\section{CONSIDERAÇÕES FINAIS}




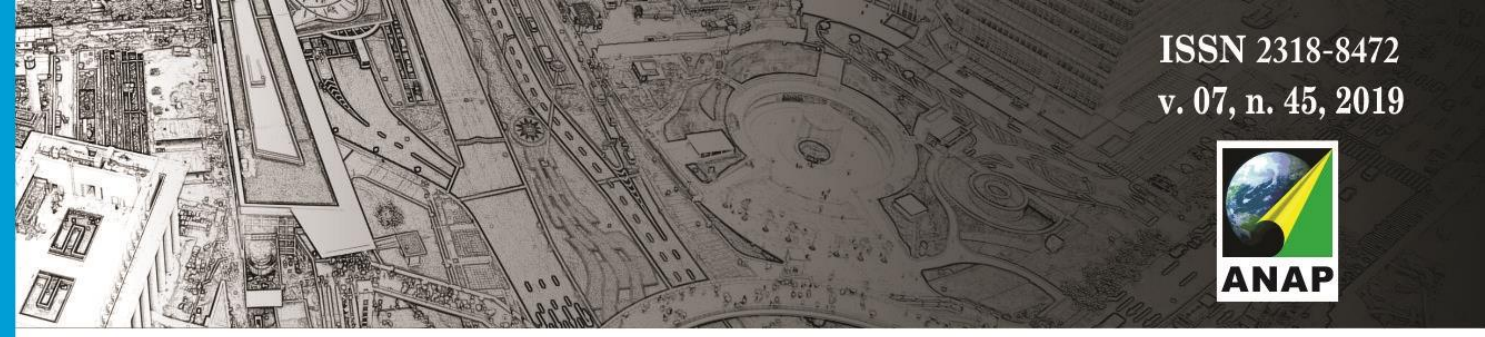

Revista Nacional de

Gerenciamento de Cidades

Tendo em vista que o município de Visconde do Rio Branco teve iniciada em 2018 a revisão do PDVRB torna-se necessário avaliar o conteúdo do plano vigente e identificar aspectos ausentes. Devido ao forte caráter cultural de Visconde do Rio Branco e tendo em vista as dificuldades encontradas na preservação do patrimônio histórico municipal, foram analisados dispositivos do Plano Diretor de 2006, relacionados à preservação do Patrimônio Cultural. O conteúdo relacionado à Preservação é insuficiente. A maior parte dos dispositivos analisados foi considerada não constatável. Isso pode fazer com que o cumprimento do plano não aconteça de forma integral, pois remete à não obrigatoriedade. Além disso, a atribuição da regulamentação de normas a outros documentos dificulta o cumprimento da atribuição pelos gestores envolvidos com o assunto.

A inexistência de leis de zoneamento e de controle do uso do solo, como também de uma fiscalização eficiente, faz com que os funcionários da prefeitura que trabalham com questões urbanas fiquem sem respaldo na tomada de decisões. Isso acentua o crescimento desordenado do município e a ameaça ao desaparecimento das qualidades de uma cidade com as marcas de sua história.

O crescimento atual sem regras causa o comprometimento de seu patrimônio cultural, que caracteriza e contribui para as atividades que conferem identidade a Visconde do Rio Branco. $O$ Conservatório Estadual de Música, assim como o conjunto da Praça 28 de Setembro, são exemplos de bens patrimoniais importantes a serem preservados.

Dessa forma, ressalta-se a importância da elaboração de políticas urbanas claras, detalhadas, e aplicáveis à realidade, pois, mais que a proposição de instrumentos urbanísticos, cabe seu entendimento pela população em geral, e não apenas por uma parcela com interesses específicos. Isso é importante para que o município se desenvolva baseado em boas políticas, que auxiliem em um crescimento sustentável.

\section{REFERÊNCIAS BIBLIOGRÁFICAS}

BRASIL. Estatuto da Cidade: guia para a implementação pelos municípios e cidadãos. Brasília: Câmara dos Deputados, 2001.

BRASIL, Ministério das Cidades. Plano Diretor Participativo: guia para elaboração pelos Municípios e cidadãos. 3a ed. Brasília: ministério das Cidades; Confea, 2008.

CASTRIOTA, Leonardo Barci. Patrimônio Cultural: Conceitos, Políticas, Instrumentos. São Paulo: Annablume, 2009.

CELESTINO, Lívia Fraga. Planejamento urbano em “cidades históricas”: um desafio necessário. In: III SIMPÓSIO CIDADES MÉDIAS E PEQUENAS DA BAHIA, 2012, Feira de Santana. Anais... Feira de Santana: UESB, 2012.

FERREIRA, Anderson Saccol. O plano diretor como instrumento de planejamento do patrimônio histórico, cultural e arquitetônico em pequenos municípios. Unoesc \& Ciência, Joaçaba, v. 8, n. 1, p. 77-84, jan-jun. 2017. 
